\title{
On Adapting a Small PM Wind Generator for a Multiblade, High Solidity Wind Turbine
}

\author{
M. A. Khan, Student Member, IEEE, P. Pillay, Fellow, IEEE, and K. D. Visser
}

\begin{abstract}
This paper explores the design space that exists between multiblade, high-solidity water-pumping turbines and modern high-speed two and three-bladed horizontal axis wind turbines (HAWTs). In particular, it compares the features and performance of a small 12-bladed, high-solidity HAWT to that of a modern three-bladed HAWT. It also outlines a procedure for adapting a small PM wind generator, intended for high-speed operation with a three-bladed HAWT for low-speed operation with a 12-bladed, high-solidity HAWT. This is achieved through a detailed analysis of the effects of several minor changes to the nominal design of the machine. The redesigned machine is shown to be capable of delivering rated power at the reduced speed required by the 12-bladed HAWT, while operating at good efficiency. The overall system performance of the 12-bladed HAWT, coupled to the redesigned wind generator, is shown to be satisfactory. Experimental validation is provided.
\end{abstract}

Index Terms-permanent-magnet (PM) generators, wind energy.

\section{INTRODUCTION}

$\mathbf{S}$ MALL wind turbines have largely adopted the threebladed, low solidity design philosophy of large utility-scale wind turbines. Increasing the number of blades has been shown theoretically to increase the aerodynamic efficiency of a wind turbine. An increase in aerodynamic efficiency could have the potential to decrease the overall cost of energy from a small wind-energy conversion system (WECS). This paper examines the design space that exists between multiblade, high-solidity water-pumping turbines and modern high-speed two and three-bladed horizontal axis wind turbines (HAWTs). Furthermore, it compares the features and performance of a small 12-bladed, high-solidity HAWT to that of a modern three-bladed one. The 12-bladed turbine operates at a lower tip speed ratio, thereby providing quieter operation, fewer balancing and vibration issues, less blade erosion, and easier starting characteristics.

This paper also addresses the problem of adapting a PM wind generator, intended for high-speed operation with a small three-bladed HAWT, for low-speed operation with a small multiblade, high-solidity HAWT. The new wind generator is required to deliver the same rated power as the original

Manuscript received November 12, 2003; revised May 21, 2004. Paper no. TEC-00332-2003.

M. A. Khan is with the Department of Electrical Engineering, University of Cape Town, Cape Town 7701, South Africa.

P. Pillay is with the Department of Electrical and Computer Engineering, Clarkson University, Potsdam, NY 13699 USA (e-mail: pillayp@ clarkson.edu).

K. D. Visser is with the Department of Mechanical and Aeronautical Engineering, Clarkson University, Potsdam, NY 13699 USA.

Digital Object Identifier 10.1109/TEC.2005.847952 machine, but at $45 \%$ of the original shaft speed, under rated wind speed conditions. This requirement translates to a $122 \%$ increase in the developed torque and, hence, a $122 \%$ increase in the rotor volume $\left(D^{2} l\right)$ of the machine. A complete redesign of the machine would ordinarily be necessary to meet these stringent requirements. However, this paper offers an alternative approach to a complete redesign of the machine. It addresses the problem of adapting an existing wind generator to meet the new requirements, through carefully analyzing the effects of several minor changes to the machine design, before selecting a new design specification for the machine. In doing so , the new machine fully exploits existing WECS manufacturing infrastructure and components in an effort to reduce the energy costs associated with the generators.

The performance and equivalent circuit parameters of the machine are assessed by means of a comprehensive analytical model of a PM synchronous machine (PMSM). The accuracy of the model has been verified experimentally and through finite-element analysis (FEA). The analytical model is used in conjunction with the terminal voltage characteristic and operating power capability of a PMSM to evaluate the effects of the design changes on the machine's performance.

\section{Multiblade High-Solidity Wind TuRbines}

The design space for wind turbine rotors, in particular, HAWTs, is quite large. Solidity ( $\sigma$-the ratio of total rotor blade area to swept area), blade number $(B)$, airfoil characteristics, and tip speed ratio $(\lambda)$ are all factors that determine the aerodynamic performance of the rotor. Reference [1] presented a comparison of approximate turbine power coefficient $\left(C_{P}\right)$ versus tip speed ratio for a wide range of machines, including HAWTs and vertical axis wind turbines (VAWTs) and is shown in Fig. 1. It can be seen that the highest overall $C_{P}$ curve is for a two-bladed high speed rotor with tip speed ratios in the range of $\lambda=4-7$. Most modern three-bladed HAWTs have similar $C_{P}$ characteristics, and are designed with low solidities, typically of $7 \%$ or less. The American multiblade turbine illustrated in Fig. 1 exhibits generally poor $C_{P}$ performance at a lower tip-speed ratio range than the high-speed two and three-bladed HAWTs. Multiblade turbines typically have high solidities and use aerodynamic drag to develop high torques for mechanical water-pumping applications [2]. The four-bladed Dutch turbine occupies a low-performance space between the previously mentioned HAWT types, likely because they did not employ the airfoil or rotor design methodologies of modern HAWTs.

A large gap can be seen to exist in the performance and operating range between the multiblade and low blade number turbines. Moreover, the ideal efficiency curve presented in Fig. 1, 


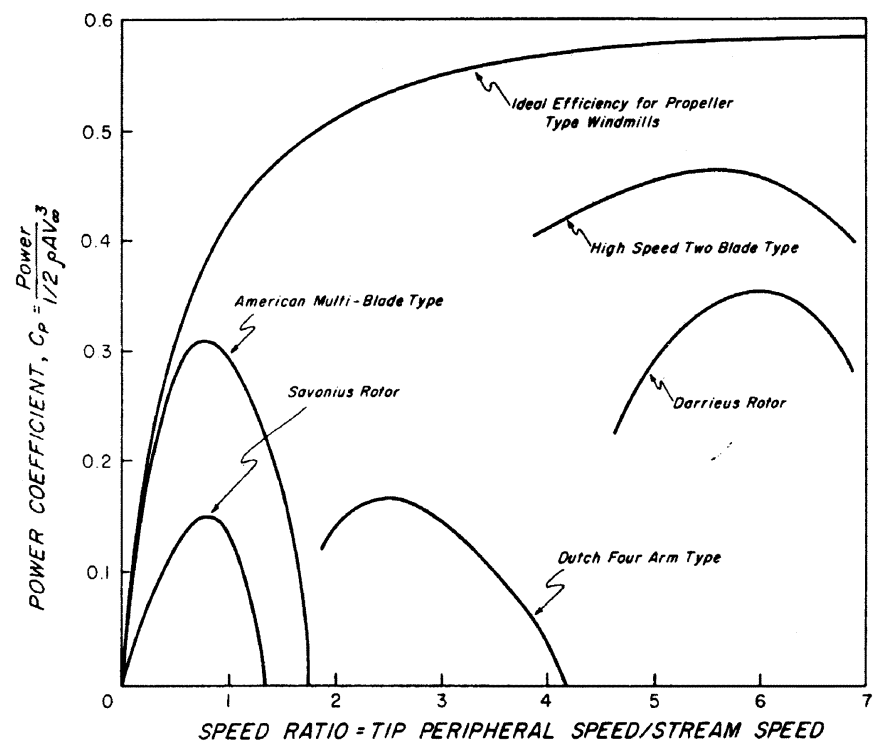

Fig. 1. $C_{P}$ versus $\lambda$ for various types of wind turbines [1].

which is based on the General Momentum theory, indicates that it is theoretically possible for a properly designed rotor to exhibit as high or higher $C_{P}$ characteristics than the current highspeed turbines at approximately half of the tip speed ratios. A study was therefore conducted to explore the design space that exists between high-solidity water-pumping turbines and the high-speed two and three-bladed turbines [3], [4]. In particular, the study focussed on using the same design principles used in the high-speed turbine designs to investigate the impact of solidity and turbine blade number on the performance of a small HAWT.

\section{A. Effect of Blade Number and Solidity on HAWT Performance}

A blade-element momentum (BEM)-based optimum design routine from [5] was first used to investigate the impact of solidity and turbine blade number on the performance of a small HAWT with optimally designed blades. Fig. 2 shows maximum power coefficient $\left(C_{P \max }=C_{p}\left(\lambda_{\text {opt }}\right)\right)$ versus tip speed ratio at $C_{P \max }\left(\lambda_{\mathrm{opt}}\right)$ for each optimum design. The analysis verified that a three-bladed turbine, designed for a high tip speed ratio of $\lambda=5-7$ should have a solidity of $5 \%$ to $7 \%$. Moreover, high tip speed ratios were shown to be more optimal for a three-bladed rotor. As shown for the six and 12-bladed cases in Fig. 2, increasing the blade number at the high design point $\lambda$ would increase $C_{P \max }$, with a diminishing return. Moreover, decreasing the design point $\lambda$ would further increase $C_{P \max }$. The highest $C_{P \text { max }}$ for the cases studied was found to be 0.523 at $\lambda_{\text {opt }}=3.75$, with $\sigma=14 \%$ and $B=12$. It should be noted that these results are based on an idealized blade-element technique [3].

Optimum designs use complicated nonlinear twist and chord distributions, but small HAWTs are often constructed with nontwisted, constant chord blades for ease of manufacture. Blades are then pitched at an angle $(\beta)$ that gives best overall performance. Fig. 3 shows a comparison of maximum $C_{P}$ versus solidity for a series of rotors with nontwisted, constant chord

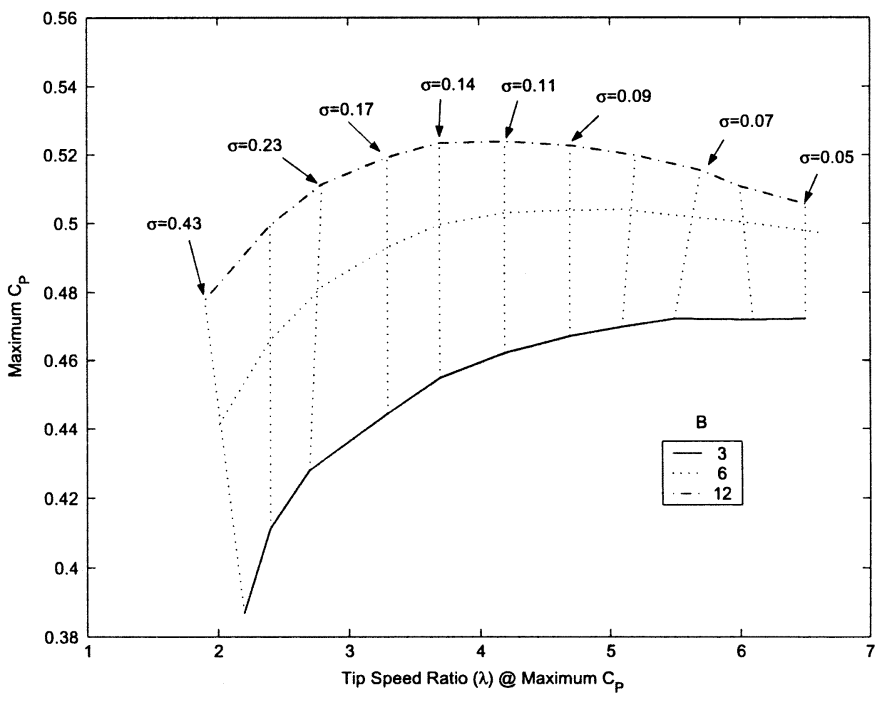

Fig. 2. Effect of turbine blade number $(B)$ and solidity $(\sigma)$ on $C_{P \text { max }}$ and $\lambda_{\text {opt }}$, for a small HAWT with optimally designed rotor blades [3], [4].

blades. The curves in Fig. 3 were obtained from a BEM analysis technique described in [3], and are shown for comparison. Unlike the optimum designs in Fig. 2, constant-chord, untwisted blades were observed to produce the highest points of maximum $C_{P}$ at a higher solidity than the optimum design solution in both the three and 12-bladed cases. For $B=12$, the highest $C_{P \text { max }}$ was 0.44 at a solidity of $\sigma=25 \%$ and a pitch angle of $\beta=12^{\circ}$. Although the difference in maximum $C_{P}$ is small between solidities, Fig. 4 shows that the tip speed ratio decreases significantly with increasing solidity, almost independently of the blade number.

Wind tunnel experiments were conducted on a scale model HAWT with flat-plate, constant-chord, nontwisted blades, to experimentally verify the trends in $C_{P}$ versus solidity and blade number [3], [4]. The experimental data confirmed that increasing solidity increased $C_{P}$, while decreasing $\lambda$ at the point of maximum $C_{P}$. The experiments also indicated that changes in blade number had little effect on the $C_{P}$ characteristics at a given solidity. This was, however, mainly attributed to the low Reynolds number range of operation and the thickness-to-chord ratio of the flat plate turbine blades used in the experiments [3].

\section{B. Operation of Small Multiblade, High-Solidity HAWTs}

With reference to Figs. 3 and 4, the highest $C_{P \text { max }}$ for a small multiblade, high-solidity HAWT was 0.44 . This was achieved by a 12-bladed HAWT, with a solidity of $\sigma=25 \%$, at a tip speed ratio of $\lambda_{\text {opt }}=2.7$. In contrast with the 12-bladed turbine, a three-bladed turbine with a low solidity of $\sigma=5 \%$, which is typical for these HAWTs, achieves a $C_{P \max }=0.39$, at $\lambda_{\text {opt }}=6$. Thus, for the same turbine blade diameter and wind speed conditions, the 12-bladed turbine will capture approximately $13 \%$ more energy than the three-bladed turbine when each are operated at the respective tip speed ratios which ensure maximum energy capture. The increased energy capture of the 12-bladed turbine is, however, achieved at $45 \%$ of the operating speed range of the three-bladed turbine.

For the same output-power rating, a generator coupled to the 12-bladed turbine will therefore be required to develop $122 \%$ 


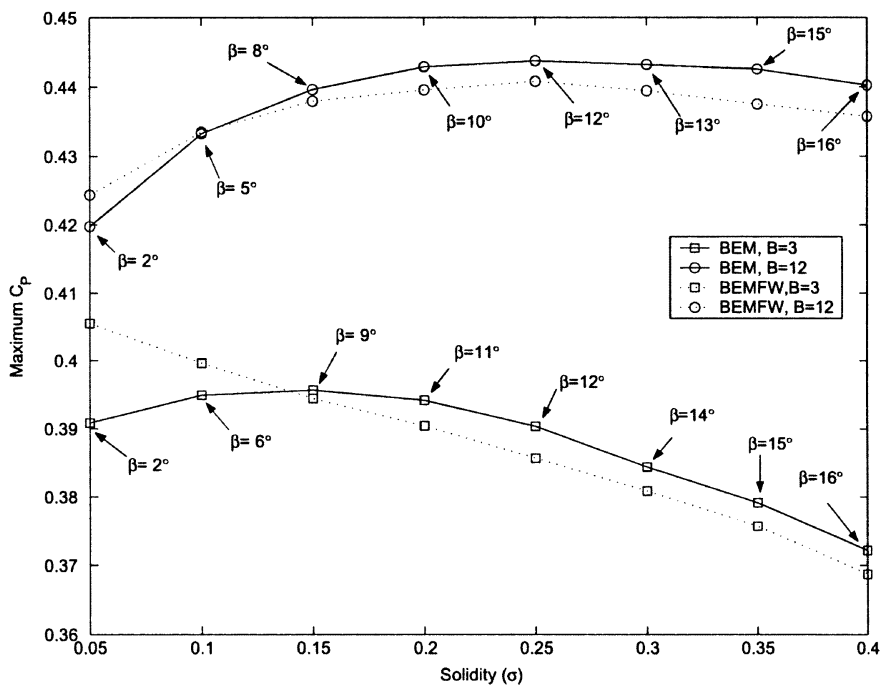

Fig. 3. Effect of turbine blade number $(B)$, blade pitch angle $(\beta)$, and solidity $(\sigma)$ on $C_{P \max }$ of a small HAWT [3], [4].

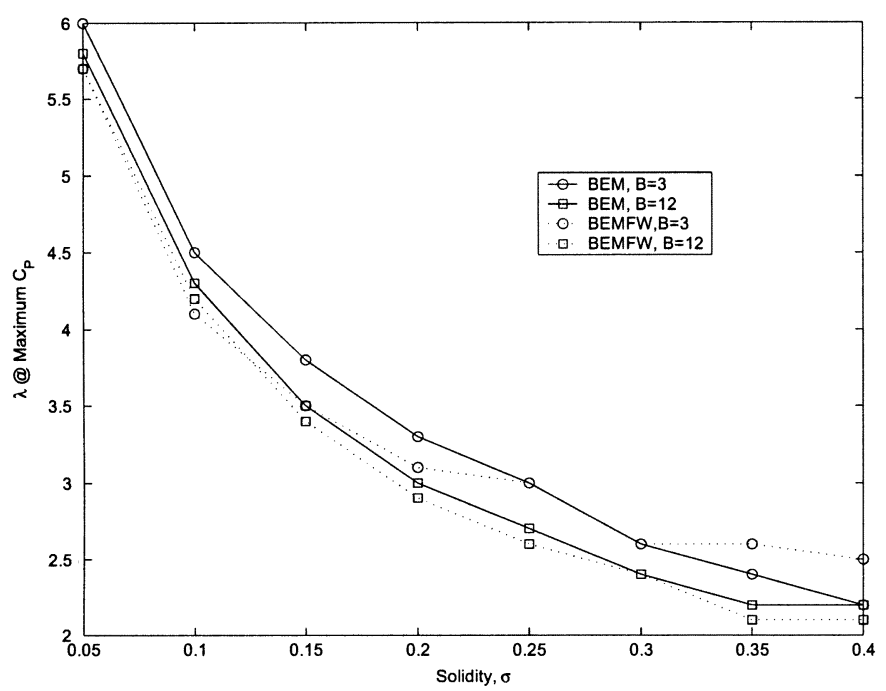

Fig. 4. Effect of turbine blade number $(B)$ and solidity $(\sigma)$ on tip speed ratio at $C_{P \max },\left(\lambda_{\mathrm{opt}}\right)$ for a small HAWT [3], [4].

more torque, compared to when coupled to the three-bladed turbine. This requirement can be met by a proportionate increase in rotor volume $\left(D^{2} l\right)$, which would ordinarily require a complete redesign of the machine. However, the alternative approach considered in this paper relates to adapting the nominal design of the wind generator to meet the new requirement. This is achieved through carefully analyzing the effects of several minor changes to the nominal design, before selecting a new design specification for the machine.

The generator is a $3.5-\mathrm{kW}$, eight-pole, $750-\mathrm{r} / \mathrm{min}$, three-phase PMSM. The output-power rating of the machine is derated for operation as a wind generator coupled directly to the aforementioned three-bladed HAWT. It is assumed that the three-bladed turbine has a $3.29-\mathrm{m}$ blade diameter and achieves its maximum $C_{p}$ of 0.39 at a tip speed ratio of 6 . Moreover, the rated wind speed is $10 \mathrm{~m} / \mathrm{s}$. Using the definition for the tip speed ratio [6], the reduced operating speed of the PM machine as a wind generator is calculated as $348 \mathrm{r} / \mathrm{min}$. The output-power rating of the machine at this speed is then calculated to be $1.625 \mathrm{~kW}$. In coupling this generator to the 12-bladed HAWT, it is still required to deliver $1.625 \mathrm{~kW}$ to its load, but at a reduced speed of 157 $\mathrm{r} / \mathrm{min}$, under rated wind speed conditions.

\section{ANALytical Model of A PM Synchronous Machine}

An analytical model of a small PMSM is used to investigate the effect of design changes on the machine performance. The model relates the mechanical design specifications of the machine to its performance and equivalent circuit parameters. It neglects magnetic saturation, which is not considerable in a surface-mounted PM machine.

The machine has radially magnetized NdFeB PMs mounted on the surface of a solid mildsteel rotor core. The resulting air-gap flux density is approximately rectangular in shape. The machine stator has a fully pitched, distributed, double-layer three-phase winding accommodated in semiclosed oval slots.

\section{A. Excitation Voltage}

The root-mean-square (rms) value of the fundamental component of the excitation voltage induced in a phase winding of the machine can be expressed as [7] and [8]:

$$
E_{f}=\frac{2 \pi}{\sqrt{2}} f N_{\mathrm{ph}} K w_{1} \phi_{p}
$$

where $K_{w 1}$ is the fundamental harmonic winding factor and $\phi_{p}$ is the flux per pole due to the fundamental space harmonic component of the excitation flux density distribution.

The flux per pole can be expressed as [7]:

$$
\phi_{p}=B_{1 \max } l D / p
$$

where $B_{1 \text { max }}$ is the peak value of the fundamental space harmonic component of the excitation flux density.

$B_{1 \text { max }}$ can be related to the plateau value $B_{g}$, of the rectangular air-gap flux density distribution, as follows [9]:

$$
B_{1 \max }=k_{f} B_{g}
$$

where $k_{f}$ is the form factor of the excitation field.

For a single PM per pole, $k_{f}$ can be expressed as [9]:

$$
k_{f}=\frac{4}{\pi} \sin \left(\frac{\alpha \pi}{2}\right) .
$$

The plateau value of the excitation flux density distribution can be related to the remanent flux density and the relative permeability of the PMs by the following expression [7], [10]:

$$
B_{g}=\frac{l_{m} / \mu_{r}}{l_{m} / \mu_{r} \cdot 1 / C_{\phi}+K_{c} l_{g}\left(1+p_{r 1}\right)} \cdot B_{r}
$$

where $C_{\phi}$ is the flux focusing factor, $K_{c}$ is Carter's coefficient, and $p_{r 1}$ is the normalized rotor leakage permeance.

\section{B. Synchronous Reactance}

The effective air gap in a PMSM with magnets mounted on the rotor surface can be considered constant and relatively large. This is due to the relative permeability of the PM material being 
close to unity. The $d$ and q-axis synchronous reactances are consequently identical in this machine. The synchronous reactance is related to the magnetizing $\left(X_{m}\right)$ and leakage $\left(X_{l}\right)$ reactances as $X_{s}=X_{m}+X_{l}$.

The magnetizing reactance can be expressed as [7]:

$$
X_{m}=\frac{6 \mu_{o} l D f K w_{1}^{2} N_{\mathrm{ph}}^{2}}{p^{2}\left(K_{c} l_{g}+l_{m} / \mu_{r}\right)}
$$

where the term $K_{c} l_{g}+l_{m} / \mu_{r}$ in (6) represents the effective air-gap length in the path of the magnetizing flux. This includes the mechanical air-gap clearance modified by Carter's coefficient to account for slotting.

The leakage reactance can be written in terms of the specific permeance coefficients associated with the dominant leakage flux paths of the stator (i.e., the slot, tooth-top, and winding overhang leakage flux paths, as [8] and [10]:

$$
X_{l}=4 \pi \mu_{o} f \frac{N_{\mathrm{ph}}^{2} l}{p q}\left(\lambda_{\text {slot }}+\lambda_{\text {tooth-top }}+\lambda_{\text {overhang }}\right) .
$$

\section{Armature Resistance}

The per-phase resistance of the stator winding, neglecting the skin effect, can be expressed as [9]:

$$
R_{a}=\frac{l_{\mathrm{ph}-\mathrm{wndng}}}{a \cdot \sigma_{\mathrm{cu}} \cdot A_{\mathrm{cond}}}
$$

where $l_{\mathrm{ph}-\text { wndng }}$ is the total length of a phase winding.

\section{Machine Performance}

The efficiency of the PMSM operated as a generator can be expressed as $\eta=P_{L} / P_{\text {shaft }}$, where $P_{\text {shaft }}$ is the input mechanical power and $P_{L}$ is the total real power delivered to its load. The input and load powers can further be related by:

$$
P_{\text {shaft }}=P_{L}+P_{\mathrm{Cu}}+P_{\text {rot }}+P_{\text {core }}
$$

where $P_{\mathrm{Cu}}$ is the total stator copper losses, $P_{\text {rot }}$ is the total rotational losses, and $P_{\text {core }}$ is the total core losses.

The total real power delivered to a load on the generator can be expressed as [8]:

$$
P_{L}=3 V_{a} I_{a} \cos \phi .
$$

The total stator copper losses can be expressed as:

$$
P_{\mathrm{Cu}}=3 I_{a}^{2} R_{a} .
$$

The total rotational losses consist of friction losses in the bearings $P_{\text {friction }}$ and windage losses $P_{\text {windage. The total rota- }}$ tional losses can therefore be written in terms of its component losses as $P_{\text {rot }}=P_{\text {friction }}+P_{\text {windage }}$.

The total core losses in the machine can be estimated on the basis of the hysteresis loss densities in the stator teeth and yoke $\left(p_{\text {ht }}, p_{\text {hy }}\right)$, and the average eddy current loss densities in the stator teeth and yoke $\left(\bar{p}_{\text {et }}, \bar{p}_{\text {ey }}\right)$. The total core losses can therefore be expressed as [10] and [12]:

$$
P_{\text {core }}=V_{\text {teeth }}\left(p_{\text {ht }}+\bar{p}_{\text {et }}\right)+V_{\text {yoke }}\left(p_{\text {hy }}+\bar{p}_{\text {ey }}\right)
$$

where $V_{\text {teeth }}$ and $V_{\text {yoke }}$ are the volumes of the stator teeth and yoke, respectively.

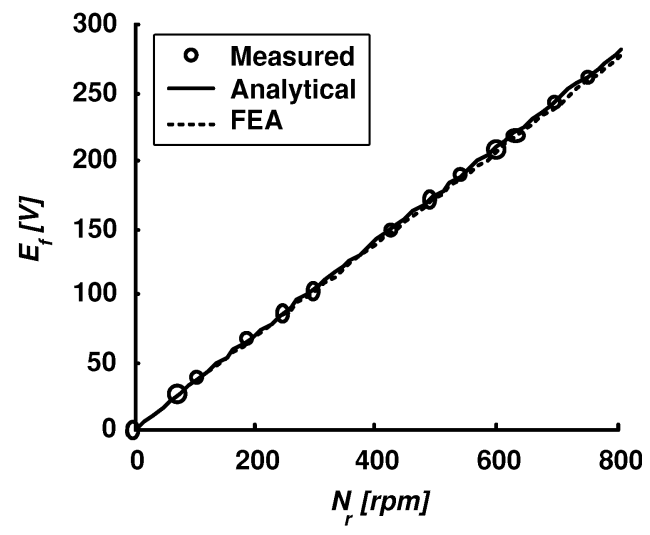

Fig. 5. Comparison of measured and calculated rms value of the fundamental excitation voltage at various rotor speeds $\left(N_{r}\right)$.

TABLE I

COMPARISON OF MEASUREd AND CALCUlated Equivalent CirCUIT PARAMETERS FOR THE TEST MACHINE

\begin{tabular}{l|c|c|c}
\hline & Measured & Analytical & FEA \\
\hline$\phi_{p}[\mathrm{wb}]$ & 0.002264 & 0.002293 & 0.002303 \\
\hline$E_{f}[\mathrm{~V}]$ & 258.77 & 262.18 & 263.13 \\
\hline$R_{a}[\Omega]$ & 1.317 & 1.571 & - \\
\hline
\end{tabular}

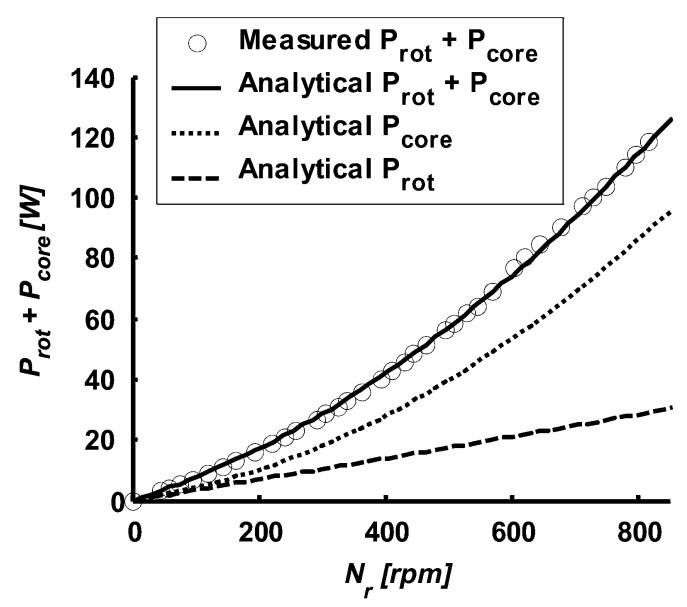

Fig. 6. Variation of core and rotational losses with speed.

\section{EXPERIMENTAL VALIDATION OF the ANALYTICAL MODEL}

The analytical model of a PMSM is verified by comparing calculated equivalent circuit parameters and power losses to measured values. The test machine used to verify the analytical model had six discrete $4 \times 10 \times 50$-mm NdFeB PMs per pole with 1-mm spacing between PMs, instead of a single smooth PM as assumed in the analytical model. The form factor of the excitation field (4) was thus modified to account for the discrete PMs per pole [9], [11]. The resulting rms value of the fundamental excitation voltage calculated for this machine was compared with that predicted by FEA and the measured voltage at various speeds, see Fig. 5.

The calculated and measured flux per pole, armature resistance, and excitation voltage at $50 \mathrm{~Hz}$ are shown in Table I.

The variation of calculated and measured core and rotational losses with speed are illustrated in Fig. 6. 
From the results presented in this section, it can be seen that good agreement exists between the calculated and measured equivalent circuit parameters and losses of the test machine, thereby verifying the analytical model of the PMSM.

\section{Terminal Voltage Characteristic and Operating CONDITIONS OF A SMALl PM Wind GENERATOR}

It is assumed that the generator is connected to a power-electronic converter, which operates as an active rectifier. The armature current of the generator is thus assumed sinusoidal and controlled by the converter. Moreover, the perceived load power factor at the terminals of the machine is also controlled by means of the converter. Under steady-state conditions, the converter can therefore be fully characterized by the generator armature current $I_{a} \angle \phi$ demanded by a fictitious load $Z_{L}$, connected to each phase of the generator.

\section{A. Terminal Voltage Characteristic}

The steady-state terminal voltage $\left(V_{a}\right)$ of the generator can be determined by considering its per-phase equivalent circuit and phasor diagram. For a machine with negligible saliency, this can be expressed as:

$$
\begin{aligned}
V_{a}=\sqrt{E_{f}^{2}-\left(I_{a} X_{s} \cos \phi\right.} & \left.+I_{a} R_{a} \sin \phi\right)^{2} \\
& +I_{a} X_{s} \sin \phi-I_{a} R_{a} \cos \phi .
\end{aligned}
$$

Equation (13) can be used to plot a family of curves to illustrate the variation of the generator terminal voltage with equivalent circuit parameters.

\section{B. Operating Conditions}

The total real power delivered to a load on the generator was given by (10). This can be used to plot $V_{a}$ versus $I_{a}$ in order for the generator to deliver $P_{L}(\mathrm{~W})$ to its load, at a specific power factor. The constant per-phase apparent power (VA) hyperbola obtained in this manner, together with the terminal voltage characteristic of the generator, determines the operating conditions of the generator when required to deliver this power to a load at various speeds. The operating currents obtained in this manner can be used to evaluate the performance of the generator at various speeds. Furthermore, it can be used to evaluate the performance of the generator when design changes are investigated to restore the output-power capability of the generator at low speeds.

\section{Effects of Design Changes on the Performance of THE PM WIND GENERATOR}

The 3.5-kW, 750-r/min PMSM under investigation is intended for operation as a wind generator, directly coupled to the small three-bladed HAWT. The machine is consequently derated to $1.625 \mathrm{~kW}$, at $348 \mathrm{r} / \mathrm{min}$. In coupling this machine to a multiblade, high-solidity HAWT, it is required to deliver $1.625 \mathrm{~kW}$ to its load, but at $157 \mathrm{r} / \mathrm{min}$ under rated wind speed conditions.

The output-power capability of the PM wind generator at this low speed can be ensured through several design changes. In particular, the effects of changes to $N_{\mathrm{ph}}, l, \alpha, B_{r}$, and $A_{\text {cond }}$ are

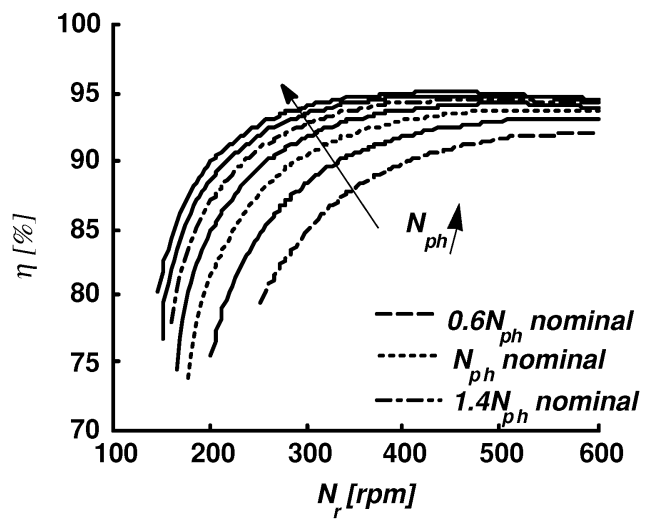

Fig. 7. Effect of a change in $N_{\mathrm{ph}}$ on the wind generator efficiency.

TABLE II

COMPARISON OF WiND GENERATOR PERFORMANCE AT FUlL LOAD, FOR CHANGE IN $N_{\mathrm{ph}}$, AT RATED AND REDUCED SPEED OPERATION

\begin{tabular}{l|l|l|l}
\hline \multicolumn{2}{c|}{} & \multicolumn{2}{c}{ Change in $N_{p h}$} \\
\hline \multirow{2}{*}{ Speed } & Performance & $1 \mathrm{x}$ & $1.4 \mathrm{x}$ \\
\hline \multirow{3}{*}{$348 \mathrm{rpm}$} & $\eta[\%]$ & 91.96 & 93.69 \\
\cline { 2 - 4 } & $S E L[A$-Cond./m] & 19,478 & 19,241 \\
\cline { 2 - 4 } & $J\left[\mathrm{~A} / \mathrm{mm}^{2}\right]$ & 1.52 & 1.072 \\
\hline \multirow{3}{*}{$157 \mathrm{rpm}$} & $\eta[\%]$ & - & 77.76 \\
\cline { 2 - 4 } & $S E L[\mathrm{~A}-$ Cond./m] & - & 47,255 \\
\cline { 2 - 4 } & $J\left[\mathrm{~A} / \mathrm{mm}^{2}\right]$ & - & 2.634 \\
\hline
\end{tabular}

investigated. Changes to these design parameters are considered minor, since they avoid the redesign and remanufacture of stator lamination stampings, as would be required by a change in $D$. The design changes are evaluated on the basis of the overall efficiency of the wind generator, its equivalent circuit parameters, the mass of active materials used, and the flux density levels in the main parts of the machine. The effect of each design change is analyzed independently, with all other parameters at nominal values.

\section{A. Change in the Number of Stator Turns Per Phase $\left(N_{\mathrm{ph}}\right)$}

The effect of this design change on the efficiency of the generator is illustrated in Fig. 7. The figure shows the variation of generator efficiency with speed, as the number of turns per phase is increased from $60 \%$ to $180 \%$ of its nominal value, in $20 \%$ intervals. The dotted line represents the variation in generator efficiency, when all of its design specifications are at nominal values.

It can be seen that the wind generator is capable of delivering rated power $(1.625 \mathrm{~kW})$ to its load at lower speeds as the number of turns per phase is increased. Moreover, the efficiency of the wind generator improves. The effect of this design change is summarized in Table II. The specific electric loading (SEL) is the rms value of the stator peripheral current density and $J$ is the stator conductor current density [8].

The relatively high efficiency at rated speed $(348 \mathrm{r} / \mathrm{min})$ in Table II is a direct result of the low operating current density due to oversized conductors, and the low armature current required due to the large excitation voltage induced in the stator winding by its many turns per phase. Increasing $N_{\text {ph }}$ makes operation at $157 \mathrm{r} / \mathrm{min}$ possible, while maintaining the relatively 


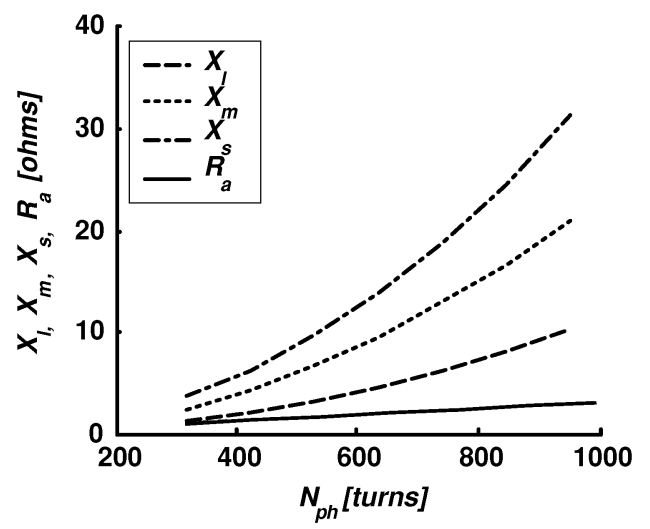

Fig. 8. Effect of a change in $N_{\mathrm{ph}}$ on equivalent circuit parameters at $348 \mathrm{r} / \mathrm{min}$.

high efficiency and low-current density. The SEL does, however, increase at this low operating speed.

The effect of a change in $N_{\mathrm{ph}}$ on the equivalent circuit parameters of the generator are illustrated in Fig. 8. It can be seen that the magnetizing and leakage reactances increase significantly, as these are proportional to the square of $N_{\mathrm{ph}}$. A $40 \%$ increase in $N_{\text {ph }}$ results in a $96 \%$ increase in the reactances. Furthermore, the armature resistance increases linearly as the total length of copper increases with $N_{\mathrm{ph}}$. The slot-fill factor increases proportionately with this design change. In assessing the machine under consideration, it was observed that the stator slots would only be able to accommodate a $10 \%$ increase in the slot-fill factor.

The mass of the copper used in the generator windings increases proportionately with $N_{\mathrm{ph}}$. The copper mass increases by $60 \%$, from 23.63 to $37.81 \mathrm{~kg}$, as $N_{\mathrm{ph}}$ is increased from its nominal value (528 turns) by $60 \%$. The mass of the stator core, rotor core, and PM material used in the machine remains constant as the number of turns is increased. The power-to-weight ratio of the generator is therefore not decreased significantly as the number of turns per phase is increased.

The flux density levels in the main parts of the machine remain within acceptable limits as $N_{\mathrm{ph}}$ is increased. The peak value in the stator teeth and yoke remain constant at 1.80 and $0.504 \mathrm{~T}$, while the plateau and peak value of the fundamental air-gap flux density are 0.756 and $0.851 \mathrm{~T}$.

\section{B. Change in the Axial Length $(l)$}

The effect of this design change on the efficiency of the wind generator is illustrated in Fig. 9. The curves show the effect on generator efficiency as the axial length is increased from $60 \%$ to $180 \%$ of the nominal value, in $20 \%$ intervals.

By comparison with the change in $N_{\mathrm{ph}}$, the change in $l$ causes the machine to operate at higher efficiency and lower, more acceptable SEL. The magnetizing reactance of the generator increases proportionately with the change in $l$, as expected from (6). The armature resistance also increases as the total length of armature winding increases with axial length. The effect of this design change on the mass of active materials used in the wind generator is illustrated in Fig. 10.

It can be seen from the figure that the total mass of the machine increases significantly by $56.83 \%$, from 67.07 to 105.18 $\mathrm{kg}$, as $l$ is increased from its nominal value by $80 \%$. Conse-

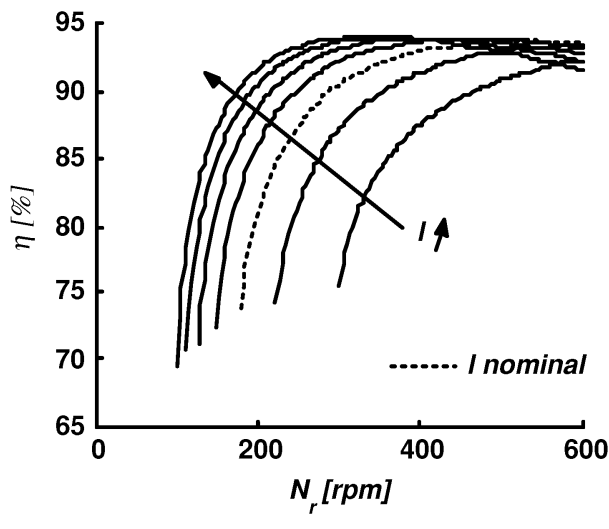

Fig. 9. Effect of a change in $l$ on the wind generator efficiency.

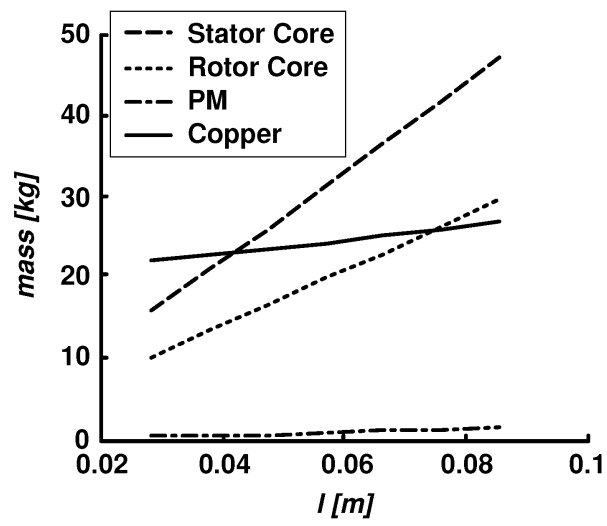

Fig. 10. Effect of a change in $l$ on the mass of active materials.

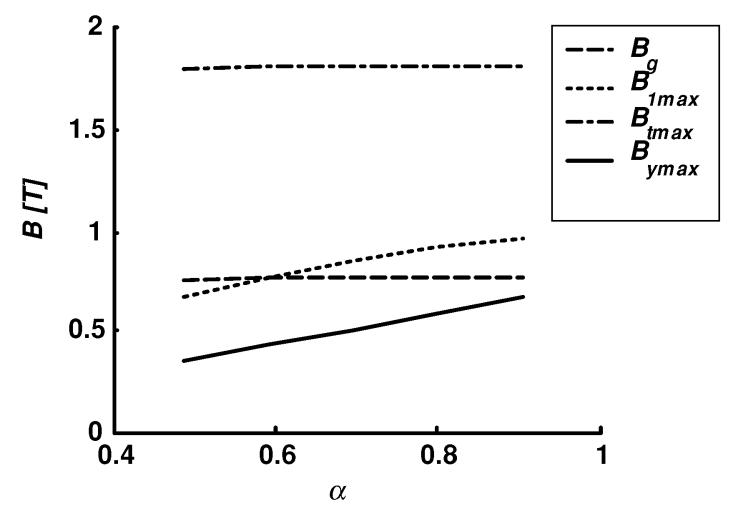

Fig. 11. Effect of a change in $\alpha$ on the flux density levels in the generator.

quently, the power-to-weight ratio of the wind generator drops by $36.24 \%$, from 24.23 to $15.45 \mathrm{~W} / \mathrm{kg}$. The flux density levels in the main parts of the machine remain similar to those quoted in the previous section.

\section{Change in the Pole-Arc to Pole-Pitch Ratio $(\alpha)$}

The equivalent circuit parameters of the generator are unaffected by this design change. The mass of the stator core, rotor core, and copper used in the machine is also not affected. However, the mass of the PM material increases proportionately with $\alpha$, from 0.753 to $0.979 \mathrm{~kg}$.

The effect of a change in $\alpha$ on the flux density levels in the main parts of the machine is illustrated in Fig. 11. It can be seen that $B_{y \text { max }}$ increases from 0.50 to $0.66 \mathrm{~T}$ and $B_{1}$ max increases 


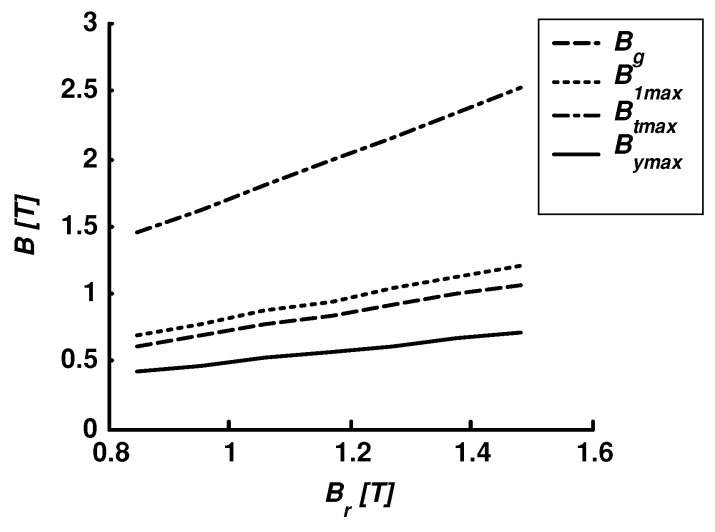

Fig. 12. Effect of a change in $B_{r}$ on the flux density levels in the machine.

from 0.85 to $0.95 \mathrm{~T}$, as $\alpha$ is increased by $30 \%$. The peak flux density in the stator teeth is also quite high, by design. These flux density levels are, however, within the allowable range for small PM machines [9], [10].

\section{Change in the Remanent Flux Density of the PMs $\left(B_{r}\right)$}

The equivalent circuit parameters and mass of the generator are unaffected by this design change. The effect of this design change on flux density levels is shown in Fig. 12. It can be seen that the peak flux density in the stator teeth increases from 1.80 to $2.53 \mathrm{~T}$ as the remanent flux density of the PMs is increased by $40 \%$. This peak value of the tooth flux density is well above the normal operating range and will cause saturation of the stator teeth.

\section{E. Change in Cross Section of Stator Conductors $\left(A_{\text {cond }}\right)$}

The reactances of the generator are unaffected by this design change. The stator winding resistance decreases, with an increase in the cross-sectional area of the conductors. The mass of copper increases proportionately by $60 \%$ from 23.63 to 37.81 $\mathrm{kg}$, as $A_{\text {cond }}$ increases by $60 \%$ from its nominal value. The slot-fill factor also increases proportionately with $A_{\text {cond }}$.

\section{MAChine ReDESIGN FOR Multiblade HIGH-SOLIDITY HAWT}

New specifications for several design parameters of the PM wind generator are discussed here. This is achieved by combining the previous changes to produce a new machine design. The new PM wind generator design obtained in this manner would therefore be capable of delivering rated power $(1.625$ $\mathrm{kW})$ at the reduced speed $(157 \mathrm{r} / \mathrm{min})$ required by the multiblade, high-solidity HAWT.

\section{A. Machine Redesign Procedure}

An increase in $N_{\mathrm{ph}}$ and $A_{\text {cond }}$ results in satisfactory full-load performance at low speeds. However, the copper mass and the slot-fill factor increases proportionately with each of these design changes. Moreover, the actual stator slots can only accommodate a $10 \%$ increase in the slot-fill factor. The reactances of the machine also increase significantly, with the square of the number of turns.
TABLE III

COMPARISON OF NOMINAL AND NEW DESIGN SPECS OF WIND GENERATOR

\begin{tabular}{|c|c|c|}
\hline Parameter & $\begin{array}{l}\text { Nominal } \\
\text { specification }\end{array}$ & $\begin{array}{l}\text { New } \\
\text { specification }\end{array}$ \\
\hline$N_{p h}$ [turns] & 528 & 370 \\
\hline$l[\mathrm{~m}]$ & 0.0475 & 0.0665 \\
\hline$\alpha$ & 0.696 & 0.905 \\
\hline$B_{r}[T]$ & 1.06 & 1.17 \\
\hline$A_{\text {cond }}\left[\mathrm{mm}^{2}\right]$ & 3.142 & 4.398 \\
\hline$R_{a}$ & 1.57 & 0.84 \\
\hline$L_{l}[m H]$ & 21.4 & 12.17 \\
\hline$L_{m}[m H]$ & 44.6 & 30.57 \\
\hline$L_{s}[\mathrm{mH}]$ & 66.0 & 42.74 \\
\hline$B_{g}[T]$ & 0.75 & 0.84 \\
\hline$B_{1 \max }[T]$ & 0.85 & 1.05 \\
\hline$B_{t \max }[T]$ & 1.80 & 2.01 \\
\hline$B_{y \max }[T]$ & 0.50 & 0.73 \\
\hline SEL [A-Cond. $/ m]$ & 19,478 & 25,578 \\
\hline$J\left[\mathrm{~A} / \mathrm{mm}^{2}\right]$ & 1.52 & 2.037 \\
\hline Total mass [kg] & 67.07 & 85.93 \\
\hline Power/weight [W/kg] & 24.23 & 18.91 \\
\hline
\end{tabular}

The constraint on increasing the axial length of the machine is the reduction in the power-to-weight ratio of the machine. Similarly, the constraint on increasing $\alpha$ and $B_{r}$ is the increase in flux density levels in the main parts of the machine. In particular, $B_{t \text { max }}$ increases significantly beyond its operating range.

In redesigning the machine, a $40 \%$ increase in $N_{\mathrm{ph}}$ and a $30 \%$ reduction in $A_{\text {cond }}$ results in a $10 \%$ net increase in the slot-fill factor and copper mass. The reduction in $A_{\text {cond }}$ can be tolerated due to the relatively low operating current density of the machine. However, in order to limit the reactances of the machine, $N_{\mathrm{ph}}$ was reduced by $30 \%$ and $A_{\text {cond }}$ increased by $40 \%$ instead. A $10 \%$ net increase in the slot-fill factor and the copper mass was therefore still maintained. Furthermore, $B_{r}$ was only increased by $10 \%$ in order to limit $B_{t \max }$ to values within the operating range for small PM machines. The pole-arc to polepitch ratio $(\alpha)$ was increased by $30 \%$, to a value of 0.905 . This increase in $\alpha$ results in a PM pole-arc of $164^{\circ}$, which borders on the limit of the range for small PM synchronous machines [10].

Since the redesigned wind generator is required to deliver rated power at $45 \%$ of its rated speed when coupled to the multibladed, high-solidity HAWT, its developed torque would increase by $122 \%$. This would ordinarily necessitate a proportional increase in the rotor volume $\left(D^{2} l\right)$ of the machine [8]. However, an increase in rotor volume can only be achieved through an increase in $l$, since changing $D$ would require the remanufacture of stator lamination stampings. The axial length was increased by $40 \%$, in order to increase the current loadings (SEL and $J$ ) of the machine, which were low in the nominal design.

\section{B. Performance of New PM Wind Generator}

The nominal and new design specifications of the wind generator are compared in Table III. It can be seen that the flux density levels in the main parts of the redesigned machine are within acceptable limits. The SEL of the new wind generator is acceptable, but $J$ is still quite low. This is primarily due to the large cross-sectional area of the stator conductors used in the 


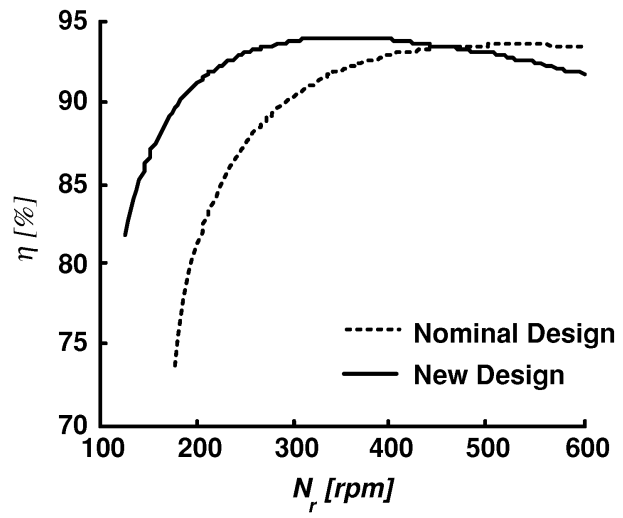

Fig. 13. Comparison of efficiency of the PM wind generator with nominal and new design specifications, at full load $(1.625 \mathrm{~kW})$.

TABLE IV

System PERFormance of THREE AND 12-BLADED HAWTS COUPLED to Wind GENERATOR WITH NOMINAL AND NEW DESIGN SPECIFICATIONS

\begin{tabular}{l|l|l}
\hline Parameter & $\begin{array}{l}\text { 3-bladed } \\
\text { HAWT }\end{array}$ & $\begin{array}{l}\text { 12-bladed } \\
\text { HAWT }\end{array}$ \\
\hline$\sigma[\%]$ & 5 & 25 \\
\hline$\lambda_{\text {opt }}$ & 6 & 2.7 \\
\hline$C_{P \max }$ & 0.39 & 0.44 \\
\hline Blade diameter $[\mathrm{m}]$ & 3.29 & 3.29 \\
\hline Rated generator power $[\mathrm{kW}]$ & 1.625 & 1.625 \\
\hline Rated speed [rpm] & 348 & 157 \\
\hline Generator efficiency $(\eta)[\%]$ & 91.96 & 87.84 \\
\hline$C_{P \max } \times \eta$ & 0.359 & 0.386 \\
\hline \multicolumn{2}{|l}{}
\end{tabular}

new design. The total mass of the new machine has, however, increased by $28 \%$, thereby reducing its power-to-weight ratio by $22 \%$.

The efficiency of the PM wind generator with nominal and new design specifications is compared in Fig. 13. It can be seen that the redesigned wind generator is capable of delivering rated power $(1.625 \mathrm{~kW})$ to its load at the low speed $(157 \mathrm{r} / \mathrm{min})$ required by the multiblade, high-solidity HAWT. Moreover, this is achieved at an efficiency of $87.84 \%$, while the machine with nominal design specifications is incapable of delivering rated power at this speed.

The overall system performance of the three and 12-bladed HAWTs coupled to wind generators with nominal and new design specifications is compared in Table IV. It can be seen that although the 12-bladed turbine captures $12.8 \%$ more energy at rated wind speed, the overall system efficiency $\left(C_{P \max } \times \eta\right)$ only increases by $7.5 \%$. This is primarily due to the drop in efficiency of the new generator design, which was constrained by practical issues relating to the nominal machine design.

\section{CONCLUSION}

This paper explored the design space that exists between multiblade, high-solidity turbines, and modern high-speed two and three-bladed HAWTs. Furthermore, it compared the performance of a small 12-bladed, high-solidity HAWT to that of a modern three-bladed design. It also outlined a procedure for adapting a small PM wind generator, intended for high-speed operation with a three-bladed HAWT, for low-speed operation with a 12-bladed, high-solidity HAWT. The redesigned machine was shown to be capable of delivering rated power at the reduced speed required by the multiblade, high-solidity HAWT, while operating at good efficiency. The overall system performance of the 12-bladed, high-solidity HAWT coupled to the redesigned wind generator was satisfactory.

\section{REFERENCES}

[1] G. L. Johnson, Wind Energy Systems. Englewood Cliffs, NJ: PrenticeHall, 1985.

[2] J. Kentfield, The Fundamentals of Wind-Driven Water Pumpers. Amsterdam, The Netherlands: Gordon and Breach, 1996.

[3] M. M. Duquette, "The Effect of Solidity and Blade Number on the Aerodynamic Performance of Small Horizontal Axis Wind Turbines," M.Sc. Dissertation, Dept. Mech. Aero. Eng., Clarkson Univ., Potsdam, NY, 2002.

[4] M. M. Duquette and K. D. Visser, "Numerical implications of solidity and blade number on rotor performance of horizontal-axis wind turbines," J. Solar Energy Eng., vol. 125, no. 4, pp. 425-432, Nov. 2003.

[5] H. Glauert, "Airplane propellers, division L," in Aerodynamic Theory, W. F. Durand, Ed. New York: Dover, 1963, vol. IV.

[6] J. F. Manwell, J. G. McGowan, and A. L. Rogers, Wind Energy Explained-Theory, Design, and Application, 1st ed. New York: Wiley, 2002.

[7] T. J. E. Miller, Brushless Permanent-Magnet and Reluctance Motor Drives. New York: Oxford Univ. Press, 1989.

[8] M. G. Say, The Performance and Design of Alternating Current Machines, 3rd ed. New York: Pitman, 1965.

[9] J. F. Gieras and M. Wing, Permanent Magnet Motor Technology: Design and Applications, 1st ed. New York: Marcel Dekker, 1997.

[10] G. R. Slemon, "Design of permanent magnet AC motors for variable speed drives," in Tutorial Course IEEE-IAS Annual Meeting, P. Pillay, Ed.. Dearborn, MI, 1991, pp. 3-1-3-35.

[11] M. Wing, "Analysis of an energy efficient permanent magnet brushless universal motor," Ph.D. dissertation, Dept. Elec. Eng., Univ. Cape Town, South Africa, 1996.

[12] G. R. Slemon and X. Liu, "Core losses in permanent magnet motors," IEEE Trans. Magn., vol. 26, no. 5, pp. 1653-1655, Sep. 1990.

M. A. Khan (S'02) received the Bachelor's and Master's degrees in Electrical Engineering from the University of Cape Town, Cape Town, South Africa, where he is currently pursuing the Ph.D. degree in electrical engineering.

P. Pillay (S'84-M'87-SM'92-F'05) received the B.Sc. and M.Sc. degrees from the University of Kwa-Zulu Natal, South Africa, in 1981 and 1983, respectively, and the Ph.D. degree from the Virginia Polytechnic Institute and State University, Blacksburg, in 1987, while funded by a Fulbright Scholarship.

From 1988 to 1990, he was with the University of Newcastle-upon-Tyne, Newcastle-upon-Tyne, U.K. From 1990 to 1995, he was with the University of New Orleans, New Orleans, LA. Currently, he is with Clarkson University, Potsdam, NY, where he is a Professor in the Department of Electrical and Computer Engineering . Since 1999, he has been an Adjunct Professor at the University of Cape Town, Cape Town, South Africa. His research and teaching interests are in modeling, design and control of electric motors and drives for industrial and alternate energy applications and power quality.

Dr. Pillay is a member of the Power Engineering, Industry Applications, Industrial Electronics, and Power Electronics Societies. He is a member of the Electric Machines Committee, Past Chairman of the Industrial Drives Committee within the Industry Applications Society, and Past Chairman of the Induction Machinery Subcommittee in the Power Engineering Society. He is a Fellow of the Institute of Electrical Engineers, U.K. and a Chartered Electrical Engineer. He is also a member of the Academy of Science of South Africa. He has organized and taught short courses in electric drives at the Annual Meeting of the Industry Applications Society. He holds the Jean Newell Distinguished Professorship in Engineering

K. D. Visser is currently an Associate Professor in the Department of Mechanical and Aeronautical Engineering, Clarkson University, Potsdam, NY. 